\title{
Aprendizagem experiencial na formação de gestores socioambientais
}

\section{Experencial learning in formation of leaders in social and environmental management}

Walterlina Brasil - Doutora em Ciências Socioambientais pelo Núcleo de Altos Estudos Amazônicos, Universidade Federal do Pará (NAEA-UFPA). Docente do Núcleo de Ciências Humanas, Universidade Federal de Rondônia (UNIR). Pesquisadora no Grupo de Estudos e Pesquisas em Educação Superior. E-mail: walterlina.brasil@gmail.com.

Solange Arrolho - Doutora em Aquicultura pelo Centro de Aquicultura da Universidade Estadual Paulista (UNESP). Professora da Universidade do Estado de Mato Grosso (UNEMAT).E-mail: solarrolho@yahoo.com.br

Berenice Simão - Mestre em Desenvolvimento Regional e Meio Ambiente pela Universidade Federal de Rondônia (UNIR). E-mail: berenicesimao@yahoo.com.br

\section{Resumo}

Trata-se da experiência proporcionada durante um curso de Pós-Graduação Lato Sensu para formação de lideranças na gestão socioambiental, onde se estabeleceu como base metodológica a Aprendizagem Experiencial, nos termos de Freire (1987), Lizeo (2003) e Kolb (1984). O artigo analisa o uso dessa abordagem no curso, e quais contribuições oferecem àqueles que se disponham a efetivar formação de gestores socioambientais. Anota-se que o curso foi estruturado com base na teoria de sistemas socioecológicos complexos, buscando contribuir com a formação de lideranças para a Amazônia brasileira. Este marco teórico é importante porque está associado à escolha metodológica para a formação oferecida, convertendo-se no eixo da proposta que abre espaço para experiências oferecidas a partir da Aprendizagem Experiencial. A análise pode subsidiar outros processos semelhantes, aperfeiçoados com base na reflexão sobre $o$ método para a aprendizagem e identificando a efetividade dessa prática na formação profissional.

\section{Palavras-chave}

Aprendizagem Experiencial. Gestão Socioambiental. Formação de Lideranças. Pós-Graduação.

\begin{abstract}
This article demonstrates the experience provided during a Lato Sensu Post-Graduation course for the formation of leaders in social and environmental management, where the Experiential Learning was established as a methodological basis, according to Freire (1987), Lizeo (2003) and Kolb (1984). Moreover, it analyzes the use of this approach within the Course, and the respective contributions to those who are willing to carry out the training of socio-environmental managers. It is noted that the course was structured based on the theory of complex socioecological systems, seeking to contribute to the formation of leaderships for the Brazilian Amazon. This theoretical framework is important because it is associated with the methodological choice for the training, becoming the axis of the proposal that broadens for Experiential Learning experiences. The analysis can support other similar processes, refined based on reflection on the method for learning, and identifying the effectiveness of this practice in vocational training.
\end{abstract}

\section{Keywords}

Experiential Learning. Environmental Management. Leadership training. Graduate Course. 


\section{INTRODUÇÃO}

O artigo contribui com os estudos sobre o uso de ferramentas metodológicas que abarcam a aprendizagem experiencial. Com este propósito e dentro do tema da conservação da Amazônia brasileira, registra e analisa a experiência do Curso de Especialização em Gestão Colaborativa de Sistemas Socioecológicos Complexos na Amazônia brasileira realizado em Mato Grosso, na cidade de Cotriguaçu, no período de 2010 a 2013. O curso teve como objetivo a formação de lideranças para gestão ambiental.

A aprendizagem experiencial foi central na proposta de condução do curso, uma vez que as mediações pedagógicas mais gerais tornaram-se cada vez mais interdependentes nas ações do grupo, quer sejam quando relacionadas ao planejamento e conteúdo, quer sejam quando relacionadas aos enfoques e intercâmbios de informação e comunicação. A execução do curso envolveu o critério de participação e colaboração entre os indivíduos para o sucesso do resultado e, disto, o quanto eram capazes de gerar estratégias de aprendizagem entre grupo e indivíduos (e vice-versa) cada vez mais consolidadas.

Assim, a aprendizagem experiencial se mostrou essencial como uma parte da formação. Portanto, aprofundar análises relacionadas ao seu uso permite avaliar o potencial dessa abordagem em situações formativas semelhantes e inferir quanto aos possíveis aprimoramentos, conforme o caso.

Com este interesse, apresentamos o resultado do exercício realizado nesta experiência de curso. Neste caso, porém, realçamos que a aprendizagem experiencial possui íntima relação com a percepção do que se compreende como gestão colaborativa, como veremos adiante. Também um resumo da proposta pedagógica, quanto à aprendizagem experiencial para o curso onde foi aplicado, é apresentado ao esclarecermos a compreensão de "Ciclo de Aprendizagem".

Em síntese, a hipótese de trabalho consiste em verificar se o Ciclo se apresenta no curso de forma progressiva, quando foi incorporando estratégias de planejamento participativo e estruturas de cogestão interna - são componentes centrais na abordagem experiencial - seria previsível que é permitido ao grupo construir uma compreensão própria quanto a limites e possibilidades da gestão colaborativa que foi concebida como tópico para reflexão permanente no processo do curso. Portanto, quando o conteúdo propõe criar situações para aquisição de instrumental teórico-prático e experiencial, a abordagem de aprendizagem experiencial pretendeu orientar o olhar do cursista sobre os grupos humanos envolvidos em conflitos relacionados ao uso e à conservação dos recursos naturais, alinhando-se a uma visão sistêmica do ambiente. Este efeito pretendido 
dependeria bastante do repertório de experiências dos cursistas e da disposição destes em colaborar.

Assim, o contexto da aprendizagem experiencial evoca a natureza e o conteúdo do projeto desenvolvido. O curso foi realizado de 2010 a 2013 e subdividido em quatro módulos presenciais, com etapas intermediárias de estudos e atividades on-line. A proposta e a implementação justificaram-se, entre outros aspectos, com a intenção de "enfrentar o desafio de conciliar conservação ambiental e desenvolvimento socioeconômico na Amazônia envolvendo diferentes áreas disciplinares, atores sociais e arranjos institucionais" (Projeto, página online do curso, 2011). Não trataremos das conclusões registradas pelos participantes do curso a respeito dos conceitos de aprendizagem experiencial e colaboração envolvidos no exercício do Módulo 3 (Brasil, W. 2012, Plano de Aplicação), porque isto se distancia dos objetivos aqui descritos. Durante o exercício, assumimos a postura de observador participante, e, desta posição, obter a coleta e realizar a análise dos dados.

Realizar um curso com um público diversificado e buscar a integração entre experiências individuais e aprendizagens coletivas, abriu espaço para reflexão sobre o resultado proporcionado, considerando a base metodológica de o projeto ser orientada para a aprendizagem experiencial. Segundo a proposta, os "participantes [eram] representativos de uma diversidade de áreas disciplinares e de experiências práticas na Amazônia, e que por isto [possibilitavam] a troca de experiências e a potencialização dos processos de aprendizagem, reflexão e aplicação dos conteúdos e métodos do curso" (Projeto, página online do curso, 2011).

Por estes dois princípios - a concepção teórica que orienta e seleciona o conteúdo em conjunto com a definição metodológica para execução - os quatro módulos visaram conduzir a identificação dos atributos, variáveis e história do sistema analisados em razão do conteúdo, ao mesmo tempo em que cada um dos envolvidos no processo poderia avançar em sua autoaprendizagem. A partir desta última reflexão, se davam acertos quanto ao planejamento e não o inverso, como usual.

No módulo 3 os grupos de trabalho convergiram para dois enfoques: questões conceituais e questões metodológicas, respectivamente. Neste sentido, o conceito de colaboração é fundamental, pois é ele que vincula conteúdo e metodologia. Por isto, a questão a ser discutida neste artigo é: em que medida e sob qual percepção dos sujeitos acerca das próprias experiências, o desenvolvimento da colaboração acontece nos processos formativos? E como se constituem como aprendizagem experiencial? 
Foi durante o planejamento e execução do módulo 3 (março 2012), que os participantes do curso assumiram de maneira mais evidente o protagonismo quanto à autoaprendizagem, como parte do conteúdo do curso. Isto confirmou as preocupações voltadas para entendimento da perspectiva metodológica, levemente sinalizada nos módulos anteriores. Os objetivos foram definidos de modo a explicitar a vinculação entre colaboração, aprendizagem experiencial e formação, como se observa no transcrito (BRASIL, 2012, Plano de Aplicação, destaques nossos):

[...] [os objetivos do Módulo 3 são]:

-Avançar no entendimento teórico-metodológico sobre a interface entre resiliência, colaboração e gestão.

-Fechar os trabalhos dos projetos de aplicação e integrar os resultados num exercício de cenários;

-Ligar a nossa experiência individual e do grupo com processos de gestão participativa/colaborativa na Amazônia;

-Sair do campo teórico e revisar aplicações práticas da nossa abordagem;

-Aprofundar conceitos ligados aos atributos nos projetos de aplicação;

-Sistematizar a nossa aprendizagem, em 3 níveis, desde o início do curso;

-Planejar uma atividade ou processo de interação com atores locais no módulo $[\ldots]$

Diante dos objetivos, pareceu-nos conveniente tomar como registro para discussão da efetividade do ciclo de aprendizagem durante a realização do módulo 3 porque este momento do curso envolveu as tarefas para execução de um estudo específico relacionado à compreensão do conceito de colaboração e construir uma ponte em relação aos grupos de atores que compunham as experiências de campo.

\section{CONCEITOS E ABORDAGENS}

O curso foi baseado na teoria de sistemas socioecológicos complexos. Segundo essa teoria, a composição do mundo em um grande sistema ecológico (recursos naturais) e social (humano) pode ser compreendido em vários subsistemas como, por exemplo: recursos hídricos, florestais, cidades e até pequenas comunidades. Estudam-se, nesta teoria, as ações do homem perante os recursos naturais e sua interação com o meio ambiente frente às intervenções de desenvolvimento econômico e os desafios de conservação e adaptação do sistema (OSTROM, 2009). 
A governança de sistemas que envolve o uso comum dos recursos não se explica exclusivamente em razão da escassez, gestão, influência de decisões comunitárias ou de governo, mas, em grande medida, da capacidade dos atores em se envolver na gestão e compreender os processos para não esgotar os recursos, reconhecer conflitos e tomar decisões racionais. São as características dos sistemas, seus atributos e os diferentes regimes em que se manifestam que promovem, internamente, resiliência e revisão dos limites do uso e os conflitos a serem tratados para sobrevivência do sistema.

\subsection{APRENDIZAGEM EXPERIENCIAL, COLABORAÇÃO E GESTÃO COLABORATIVA}

Consideramos o conceito de aprendizagem experiencial por estar ligado ao processo formador no âmbito da atuação dos indivíduos inseridos no contexto do curso, suas interações, percepções, compartilhamentos, atitudes e disponibilidades para aprendizagem colaborativa em razão de uma gestão colaborativa. Tais envolvem decisões e escala superiores à própria condição desses indivíduos, vistas no conjunto das atividades do curso, mas também a partir dos avanços compreendidos em torno da aprendizagem.

Um dos pilares para o desenvolvimento de estratégias de aprendizagem foi a acepção de Kolb (1984). Em síntese, Kolb (1984, p. 38) define aprendizagem como resultado da transformação da experiência e estabelece quatro etapas para este processo que podem ser sintetizadas no chamado "Ciclo de Aprendizagem Experiencial". Envolvem a experiência concreta, observação reflexiva, conceitualização abstrata e a experimentação ativa, buscando que o sujeito procure obter a visão sobre os efeitos relativos ao próprio comportamento de aprender, enquanto aprende.

De fato, Kolb procura estabelecer uma compreensão sobre a experiência como base da aprendizagem em adultos. Trata aspectos quanto ao significado dessas aprendizagens, os dilemas que podem ou não ser superados em relação aos estilos de aprendizagem envolvidos e modificar o comportamento, de modo a adquirir significado em torno da própria aprendizagem. A abordagem experiencial considera que o indivíduo precisa querer aprender para que efetivamente a aprendizagem ocorra. Para tanto, é preciso identificar quais dispositivos são disparados quando o indivíduo se confronta com os conteúdos a serem aprendidos. No curso, os aspectos relacionados ao repertório a ser disponibilizado ou acessado entre os cursistas é previsto durante a composição da turma e considerando-se os cursistas também atores experientes cuja memória e 
história pessoal evocará experiências a serem verificadas, questionadas e trocadas de forma autônoma e interessada para que o processo que está sendo oferecido seja ressignificado. Não sendo considerado isto, o curso torna-se objeto em si, longe de ser objetivo coletivo.

Nesta experiência, a gestão socioambiental é o desafio formador, a partir de lideranças que possuem elementos teóricos quanto à complexidade dos sistemas socioecológicos e atores envolvidos nos dilemas da gestão colaborativa. É preciso aproximar as expectativas dos cursistas frente aos desafios formadores contidos na proposta do curso e a rede de significados a ser tecida pelos indivíduos. Ou seja, nos termos de Kolb (1984), se a experiência é transformada, a aprendizagem ocorre.

Os estudos sobre Kolb no Brasil enfatizam este aspecto da aprendizagem de adultos em processos de profissionalização. Conforme Pimentel (2007), a teoria da aprendizagem experiencial desenvolvida por Kolb é importante ser conhecida e incorporada no Brasil porque são poucas as contribuições das teorias do desenvolvimento que envolvem a relação da profissionalização em adultos e a aquisição do conhecimento. A proposta de Paulo Freire (1987; 1996), por exemplo, envolve em grande medida aspectos políticos da mediação docente em ambiente escolarizado e a consciência política promovida pelo diálogo, do que, necessariamente, identificar quais processos internos mobilizam a aprendizagem. De fato, no curso analisado, tanto o engajamento cognitivo com base na abordagem experiencial, quanto o entendimento da dimensão dialógica, com base na abordagem freireana, são complementares para avançar na concepção de colaboração, complexidade e os dilemas da gestão socioambiental.

Mas detendo-nos no conjunto das condições impostas pelas características que cursos de formação possuem, outro dado nessa concepção, é o uso da noção de mapas ou modelos mentais. Esse conceito durante o curso foi usado para explicar, justificar ou exemplificar como os indivíduos assumem determinada posição, constroem os interesses e interpretam suas relações do mundo. No estudo de Lizeo, há também uma referência a estes aspectos. Entretanto, a autora propõe uma posição para revelar estes "mapas". Segundo ela, entre a experiência concreta e a observação reflexiva há um gap, que é ocasionado por conta dos ajustes entre a experiência e a estrutura reflexiva do sujeito. A intermediação se daria a partir do uso do entendimento que deveria ser usada para operar no processo de compreensão do ambiente e da percepção das pessoas sobre o ambiente e sobre si mesmas, dentro dele ou como parte dele.

O que o indivíduo sabe ou compreende é o que ele estabelecerá na rede de estruturas que compõem o mapa conceitual. Lizeo propõe uma adaptação 
ao Ciclo de Aprendizagem em relação ao mapa conceitual e observação dos aspectos individuais no processo, mediante a inclusão da noção de Loop.

Os loops são os avanços que um grupo "se permite" a partir das reações às propostas de interação que são realizadas. Na condução da experiência, podemos inferir ou destacar processos sob os quais os indivíduos se disponibilizam para aprender. A aprendizagem em grupo reflete níveis de interdependência, confiança, compartilhamento e autonomia. Um grupo, quando aprende, não reflete o acúmulo de aprendizagem dos indivíduos, mas do acúmulo de conhecimento que pode gerar em conjunto. Um passado comum e um futuro desejado fazem parte da nuance por compor e instrumentalizar um grupo. Daí a importância de entender o Ciclo de Aprendizagem Experiencial pautada no grupo.

Desse ponto de vista, é importante identificar que existem outras extrapolações relacionadas à interação individual e coletiva nos processos de aprendizagem. No campo da psicologia social é crescente o interesse por aprendizagens que podem assumir impactos amplos e coletivos no campo do pensamento e da linguagem, especialmente quando partem do plano individual (MARKOVÁ, 2006). A psicologia organizacional acompanha esta onda, estando cada vez mais ocupada com as ferramentas para compreensão das estruturas humanas na sociedade (SIQUEIRA et al., 2008), assim como a administração, gestão e aprendizagem organizacional, no âmbito da discussão sobre as competências (RUAS; ANTONELLO; BOFF, 2005). Porém, essas questões não foram exploradas com o foco e/ou a partir experiência nem para o propósito do curso, dado parecerem secundárias, excessivamente acadêmicas ou de baixo impacto em relação ao conteúdo formativo proposto (BRASIL, W. Notas de Curso, 2011-2013). Abordagens sobre teorias de aprendizagem são bastante úteis, mas não é possível destacar todas como se tratássemos da aprendizagem em si. De fato, se tratou do registro de um processo de aprendizagem em específico, sem menção a outras possibilidades.

Sobre o Ciclo de Aprendizagem Experiencial, Lizeo (2003, p. 23) o define como "[...] um processo contínuo de reflexão e ação baseadas na compreensão compartilhada e ancoradas na experiência conjunta, tendo como resultado a geração de novos conhecimentos e de insights". Coletivamente, os membros do grupo refletem sobre os resultados de suas ações (Experiência Conjunta) por meio da Conversação Reflexiva baseada no diálogo e na discussão produtiva. A qualidade da reflexão dos membros sobre os resultados de suas ações dependerá dos Mapas Cognitivos Coletivos do grupo, incluindo sua base de conhecimento e seus modelos mentais. 
A partir da reflexão os membros do grupo desenvolvem em conjunto um Plano de Ação, que os orienta nas tomadas de decisão e na solução de problemas (Implementação da Ação). Os resultados de suas ações servem como base para futuras experimentações, completando o ciclo de aprendizagem em grupo. Entretanto, há limitações que podem ocorrer dentro do ciclo experiencial que envolvem grupos. Várias são as razões que vão desde a condução do grupo, até a disponibilidade de tempo para as tarefas, conflitos de interesses, expectativas e disponibilidade de recursos. A figura a seguir, proposta por Lizeo (2003), posiciona tais limitações dentro do Ciclo.

Figura 1 - Ciclo de Aprendizagem Experiencial em Grupo e suas limitações

\section{Ambiente}

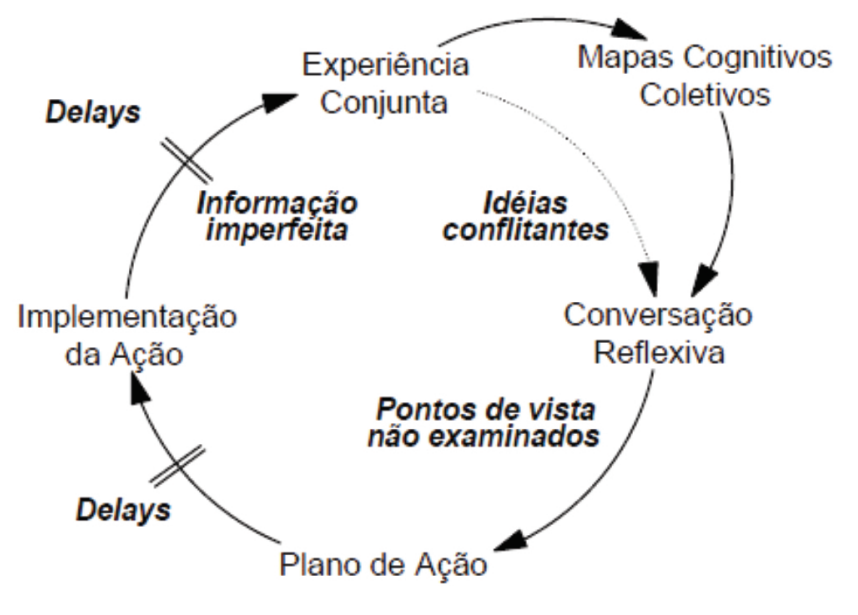

Fonte: Adaptado em Lizeo (2003, esquema 2.5 e 2.7, p. 24 e 40)

As limitações do ciclo experiencial podem incidir em ciclos incompletos. Isto significa não aprendizagem como grupo. Alguns dos elementos que contribuem para um ciclo incompleto são: ideias conflitantes, que fazem os indivíduos reativos à oposição de um pensamento em particular, exigindo negociações que, por vezes, conduzem à conformação resignada do grupo. Tensão relacionada a pontos de vista, onde a prevalência de um ponto de vista depende da posição ou imposição de um comando ou ideia específica em relação ao grupo. Delays ou "atrasos" entre a designação de tarefas, o tempo de execução ou a responsabilização do grupo em torno destas. Em um nível mais específico ou profundo, o delay vem acompanhado com informação imperfeita, quando restringe a informação a certos aspectos em lugar de outros ou a certos indivíduos em detrimento do grupo. 
Em toda a proposta do curso, as indicações propostas nas contribuições teóricas atribuídas à análise de sistemas socioecológicos complexos são que o reconhecimento da não linearidade se estabelece em função, principalmente, da possibilidade de identificar quais elementos poderiam ser constantes ("resiliência de que", no sistema) e quais diferentes atores, com diferentes interesses, em algum momento, podem convergir. Do ponto de vista da teoria freireana, a convergência não seria necessariamente fruto de um diálogo.

Assim, embora não analisemos a pedagogia de Paulo Freire com sincronia ou não à teoria de Kolb ou vice-versa, há, no conceito de diálogo, em ambos, o apelo em torno da reflexão constante sobre e em torno das ideias que conflitam em um grupo ou o reconhecimento prévio dos riscos ao diálogo, em razão da produção de informação imperfeita.

\section{METODOLOGIA}

Para o desenho da metodologia, consideramos a oportunidade de analisar a interação entre o conhecimento "em formação" de natureza acadêmica e vivencial, articulado em parte pela motivação e pela formalidade (cumprimento de tarefas e produtos dos cursistas), com a oportunidade de aprendizagem experiencial.

Por conhecimento "em formação" entendem-se os conteúdos mobilizados para a execução e movimento (processo) disponível para novas aprendizagens durante o curso. Os acessos à formação ocorrem por meio do desenho pedagógico coerente com o fundamento teórico e os objetivos a serem atingidos.

A hipótese geral de trabalho foi que os participantes do curso que estavam mobilizados para o conhecimento (no caso os cursistas e os organizadores) também possuíam relações internas (intra-grupo) e características pessoais que constituíam (ou "construíram") a dinâmica da ação grupal relacionada à própria aprendizagem e aos resultados do curso (BRASIL, 2012). Assim, poderiam, na verdade, gerar mais delays do que sofrer a influência de loops durante o processo de reflexão relacionado à aprendizagem experiencial.

Diante disto, a principal pergunta foi: qual a efetividade do uso de uma técnica didática e pedagógica como uma aprendizagem experiencial em relação a uma atividade que considera a natureza e a construção dessas relações de aprendizagem em grupo? 


\subsection{A OBSERVAÇÃO PARTICIPANTE COM EMPREGO DE REGISTRO DE FALA}

No processo metodológico empregamos a técnica da observação participante associada à coleta de fragmentos de fala. Isto significou que os registros da pesquisa cumpriam também a função de aprendizagem reflexiva das autoras ${ }^{1}$. O espaço para coleta dos dados foi indicado a partir da realização de uma atividade denominada Painel de Atores e Discussão de Cenário, cujas compreensões seriam registradas visualmente através do Mural de Conceitos. Neste último registro (o Mural) foram registrados os insights do grupo, conforme ocorrências nas discussões.

A etapas de trabalho passaram a ser:

1. Realização de atividade prática (painel, mesa, campo) de modo que o grupo tivesse um relato de experiência que envolvesse mobilização e participação de grupos.

2. Registro das reflexões do grupo em torno da percepção relacionada ao modo de como estes atores fazem a leitura do "caso" a partir da compreensão que tivessem sobre participação.

3. Indicação por parte do grupo da percepção sobre a participação, considerando os conteúdos do módulo como mobilizadores do pensamento sobre participação.

4. Registro coletivo da compreensão do grupo. Foi realizada uma dinâmica para mobilizar os participantes a revisar a construção do diálogo sobre participação ocorrido no módulo.

5. Exposição geral da experiência no momento do módulo e submissão à crítica dos participantes.

Estes itens de 1 a 4 foram cumpridos obtendo-se, mediante registro da percepção conceitual, o que o sobre a colaboração e foram orientadas em torno de fragmentos de fala. A técnica do fragmento de fala já havia sido experienciada pelo grupo na atividade de diagnóstico do sistema, desenvolvido no módulo 1 , aplicada a diversos atores sociais. O uso da técnica foi precedido de conversas informais sobre os objetivos da atividade, do projeto de aplicação em evidência e das metas da observação (BRASIL, W. 2012).

A coleta durante o Módulo 3 seguiu focada especialmente nos "atos de

\footnotetext{
"Originalmente os dados registrados foram utilizados para análise dos diversos conceitos e procedimentos associados à colaboração e a gestão colaborativa a partir do ponto de vista do ator, sem desprezar que também está presente o ponto de vista de quem intervém e interage com este ator" (BRASIL, 2012).
} 
palavra" expostos em relação à oralidade, sem entrar na voz, timbre, tons e outros elementos que constituem os modos da fala e sem adentrar no ritmo interno da palavra. Neste sentido, as palavras foram transcritas, sem marcas ou ênfases específicas relacionadas a linguagem ou uso pelos sujeitos.

\subsection{BASE ANALÍTICA}

Durante a observação participante, as autoras produziram os registros analíticos. Foram capturadas as falas que fossem produzidas durante a exposição dos convidados na atividade do Painel de atores, discutindo a experiência do Zoneamento Econômico Ecológico do Estado do Mato Grosso. Também foram destacados registros durante a atividade relacionada a metodologia de construção de Cenários, uma vez que, em ambos os casos, o foco era a reflexão em torno de tópicos onde emergissem indícios dos conceitos relacionados à participação, que era o mote para mobilizar os debates do grupo.

Os dados da coleta foram postos como frases. As frases, quando compostas, assumem explicativamente sua concepção filosófica (SOUZA E SILVA; KOCH, 1989, p. 11), em torno de um conjunto de palavras que compõem um sentido comunicativo (Dicionário de Filosofia, verbete FRASES. http:// www.defnarede.com/f. btml), com estrutura própria e distintiva da proposição que contem pensamento literal em frases declarativas (Dicionário de Filosofia, verbete PROPOSIÇÃO. http:/ / www. defnarede.com/f.html).

A meta do trabalho foi coleta de percepções dos cursistas e, conforme a viabilidade de integração destes na discussão, produzir uma reflexão sobre como tal percepção reflete na adoção do conceito de colaboração relacionada à gestão. Os cursistas não atuaram como coletores dos fragmentos de fala. Este procedimento assegurou isenção do registro, para que houvesse a possibilidade de saltar dos registros de fala para a construção de um conceito de colaboração advindo do grupo.

O destaque de proposições à luz da compreensão filosófica foi constituído a partir da etapa da análise do grupo, quando se produziu "sínteses de sentido" a partir de palavras-chave e que sofreram as críticas do grupo, de modo a produzir definições que os representassem quanto ao entendimento que tinham a partir do que ouviram, falaram e registraram.

As interpretações dadas pelo grupo às atividades desenvolvidas, sob coordenação das autoras, permitiram classificar os fragmentos de fala em proposições. Feito este exercício, a análise recorreu às definições que fossem razoáveis ao campo disciplinário - no campo científico - aos quais essas 
construções pudessem remeter. Ou seja, para o conjunto das interpretações produzidas pelo grupo, buscou-se a sua "convergência" no campo interpretativo a partir da Sociologia, da Psicologia, da Linguagem ou da Filosofia.

Um dado importante, gerado pela condução do curso, é que a decisão de interpretar os resultados obtidos na atividade deveria ser posterior ao exercício do módulo 3, mas não foi realizado o exercício de validação em grupo dos registros no módulo 4, quando os registros já haviam assumido a forma de relatório, apesar do argumento alguma conclusão deveria ser a partir do material disponibilizado na atividade do módulo 3.

Este fato foi crucial para que tivessémos elementos capazes de fazer refletir e considerar como e em que medida a aprendizagem experiencial influencia ou é influenciada por fatores externos e como se constitui a participação e apreensão das condições de aprendizagem dos sujeitos. Assim, a análise dos resultados foi orientada pela decisão de classificar os passos cumpridos no exercício em razão do Ciclo de Aprendizagem, exposto no item de análise dos resultados.

Foram previstas duas atividades dentro de um Plano de Trabalho (denominado Projeto de Aplicação), para observação participante - pelas autoras - durante uma atividade do Módulo 3 voltada a discussão do conceito de colaboração Painel de Atores e Palestra sobre Cenários. Aqui, dizemos exclusivamente sobre o Painel de Atores por envolver a construção do Mural de Conceitos pelos Cursistas considerando a realização do Painel.

A função das observadoras, além do natural envolvimento nas atividades por também serem cursistas, foi de auxiliar os registros gerais na realização das tarefas e coordenação posterior das análises.

\subsection{ANÁLISE DOS RESULTADOS}

O interesse analítico do resultado do exercício foi objeto de registro específico e partir da presença da fala. Aqui transportamos as etapas do exercício para os elementos da abordagem experiencial, baseados nos conceitos de loop e gap apresentados na discussão teórica. Dentro de uma perspectiva da aprendizagem experiencial, inserida no ciclo de aprendizagem em grupo, cada etapa da coleta a análise obedeceu a seguinte forma: 
Figura 2 - Ciclo de Aprendizagem Experiencial, limitações e localização das atividades desenvolvidas pelo estudo

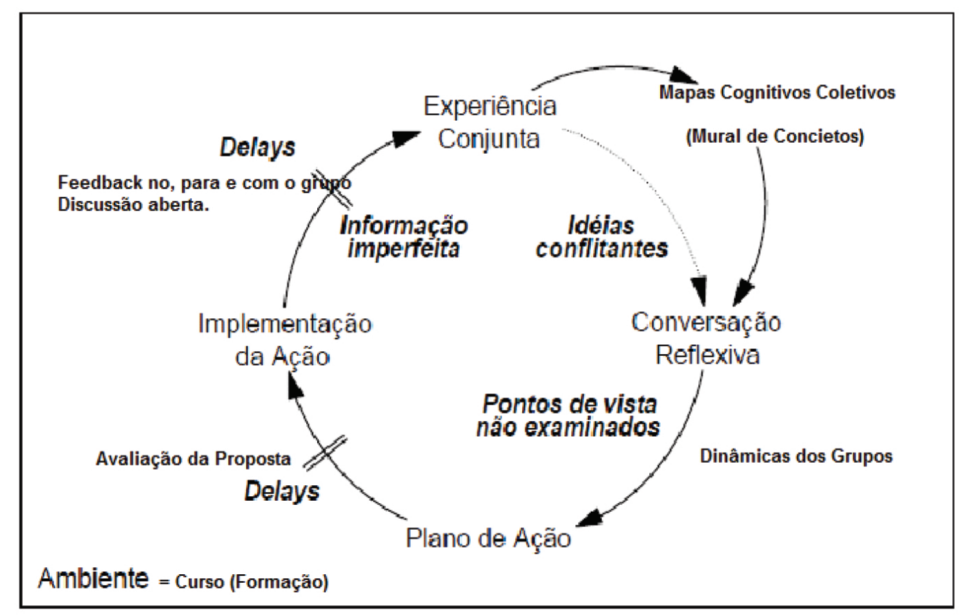

Fonte: Adaptado de Lizeo

Verificamos o histórico do curso e observamos que a principal medida de registro reflexivo foi a construção dos diários de aprendizagem, que no terceiro módulo assumiram a denominação de scrap books. Para este processo, os proponentes e coordenadores das atividades buscaram indicá-lo como um espaço de registro intimista, voluntário, espontâneo e arbitrário de anotações sobre insights, memórias e reflexões por parte do cursista. Outra estratégia, mais coletiva, foi a adoção do monitoramento que consistia no grupo revisar aprendizagens a partir da observação participante em sub-grupos que produziam feedback livres para os cursistas no início da atividade.

Figura 3 - Ciclo de Aprendizagem Experiencial

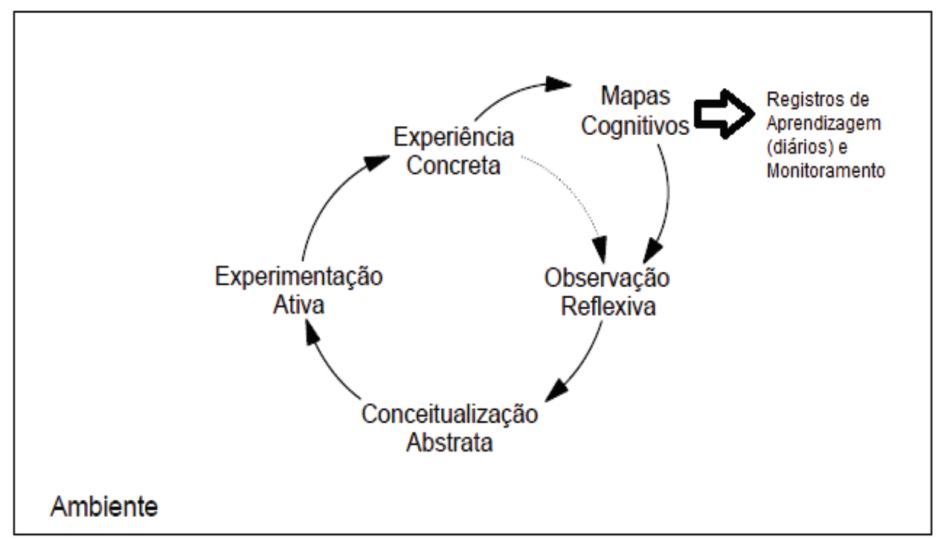

Fonte: Adaptado em Lizeo (2003, esquema 2.2, p.24) 
Consideramos as etapas do Ciclo Experiencial em Grupo com suas limitações e identificamos o processo em que o grupo desenvolveu a atividade proposta. Para cada tarefa e resultado alcançado, procuramos verificar como o grupo se comportou e quais fatores podem ser considerados em cada uma das etapas.

\subsubsection{Observação do Painel de Atores e Mural de Conceitos do Grupo}

O Painel de Atores ocorreu com representantes envolvidos na gestão de recursos naturais, no âmbito das políticas macro-sistêmicas de Mato Grosso, trocando experiências sobre o Zoneamento Socioeconômico e Ecológico (ZSEE) no estado. Assim, a atividade "Mural de Participação" teve como mobilizador o Painel de Atores relacionado à experiência do ZSEE, mas não se referiu exclusivamente a esta atividade. Ou seja, o Painel de Atores constituiu-se a atividade mobilizadora, mas sua abrangência em torno do Mural (Conceitual) sobre participação, buscou movimentar no grupo de cursistas a percepção sobre o que é participação e como este grupo expressa a percepção que possui, a como processos participativos podem ocorrer, tendo em conta um conceito para tratar a participação.

Toda a produção das análises ocorreu em forma de tempestade de ideias e debate livre. Os registros ocorreram "na hora", com correções "em tempo". Também os registros ficam disponíveis e visíveis para o público durante todo o decorrer das atividades do curso. Cada observadora anotou nas exposições orais expressões e exemplos que pudessem remeter ao grupo o que seria "participar".

Ao final do dia, as observadoras conversavam procurando construir um entendimento e destacar quais exemplos observados poderiam ser expostos para o grupo de modo a favorecer mais o debate sobre o conceito em questão e alimentar o painel. Também dessas conversas com quais sínteses iniciais poderiam ser produzidas e disponibilizadas no Mural. Isto também convenceu as autoras a produzir uma memória metodológica deste aspecto do curso, resultando no relatório.

\section{RESULTADOS E DISCUSSÃO}

Conforme apresentado anteriormente, nossa metodologia consistiu em analisar a experiência em torno do ciclo de aprendizagem em grupo, adaptado de Kolb (1984) por Lizeo (2003). Para o propósito deste artigo, algumas observações de Lizeo devem ser reforçadas. Em primeiro lugar, este ciclo não tem valor em 
si mesmo. Ele representa a necessária intermediação da pessoa em relação as suas experiências no mundo. Durante o Curso, os participantes não tiveram contato intensivo com a dimensão teórica de Kolb. Entretanto, foi assumida esta condição pedagógica no desenho do curso, combinada com princípios da educação de adultos em Paulo Freire (1987), sendo estudado e discutido dentro das atividades apenas o segundo autor.

Especialmente nos módulos 3 e 4 atuar "dentro" do ciclo de aprendizagem passou a ser crucial inclusive para o processo de planejamento, escolha dos conteúdos, sequência de abordagem e estratégias de registro. Nós entendemos então que uma reflexão importante seria exatamente entender a dimensão e a prática do ciclo de aprendizagem na atividade em grupo. Essa atividade possui especial relevo se considerarmos que o objetivo consistiu fundamentalmente em contribuir para construção coletiva e experiencial de um conceito.

A partir dessa abordagem e de acordo com análise dos registros no desenvolvimento das tarefas dentro do processo de coleta, podemos apresentar cada um dos quatro passos do ciclo.

\section{Passo 1 - Experiência Conjunta $=>$ Reflexão Conversação Reflexiva}

Idéias Conflitantes $\Leftrightarrow$ Mural de Conceitos

O Mural de Conceitos sobre o entendimento de participação foi a ferramenta proposta. A partir do mural da participação, o grupo indicaria qual o entendimento sobre um conceito de colaboração estava revelado em torno do que e como ele próprio se organizava e tomava suas decisões.

O grupo rejeitou o processo de inferência por "votação", entendendo que esse critério era uma limitante da reflexão pretendida e não havia segurança se o resultado visual no final auxiliaria ou não no resultado. Essa rejeição, porém, não se tornou um fator que remeteria ao resultado. Esteve indicado no planejamento que, a cada dia, deveria obter-se uma visão geral do conjunto pelos participantes. Isto se daria a partir da observação do processo, ocasionando uma validação para o grupo, a partir da exposição de uma síntese de modo a ir compondo o mural.

\section{Passo $2-$ Conversação Reflexiva $=>$ Plano de Ação}

\section{Pontos de Vista não-examinados $\Leftrightarrow$ Dinâmica dos Grupos}

Apesar do planejamento, das iniciativas prévias das formas de exposição e disponibilidade de conteúdo, todas as atividades previstas foram ajustadas. $\mathrm{O}$ painel foi adaptado em suas atividades iniciais e também na previsão de execução dentro da agenda do curso. Durante a exposição metodológica para o uso do mural, a pergunta do painel esteve focada em "Participação". Os cursistas 
entenderam que associar colaboração/participação em uma única questão ou abordagem a tornaria mais complexa a reflexão do que inviabilizaria o foco em cada uma das questões. O conteúdo gestão colaborativa passou, portanto, a assumir o sinônimo (ou ideia) de gestão participativa.

O grupo rejeitou o processo de inferência por "votação", entendendo que esse critério era uma limitante da reflexão pretendida e não havia segurança se o resultado visual (final) auxiliaria no resultado. Utilizou-se com maior ênfase as afirmações dos convidados do que dos membros dos grupos.

\section{Passo 3 - Plano de Ação => Implementação da Ação}

Delays ou mudanças $\Leftrightarrow$ Avaliação da Proposta

O Mural de Conceitos remetia às práticas dos cursistas como subgrupos e indivíduos dentro do curso. Devido à lacuna entre o tempo de aprovação e execução para incursão nos dados gerais e instrumentos de pesquisa, não foi possível construir um instrumento de coleta sincrônico com o planejamento, instalação e atividades dos Planos de Aplicação em coerência com a rotina dos cursistas e do curso. Assim, esta abrangência relacionada às práticas não foi possível, limitando o espaço de aprendizagem a uma oportunidade técnica com poucas possibilidades de feedback dos subgrupos internos a partir de suas experiências próprias, como sendo atores efetivamente interessantes para o grupo e envolvidos nas respectivas atividades por eles mesmos aprovada.

\section{Passo 4 - Implementação da Ação => Experiência Conjunta}

Informacão Imperfeita ó Feedback no, para e com o grupo. Discussão Aberta.

O grupo não indicou a recepção da informação, nem proveu feedback aberto sobre o tema. A análise ficou a critério da coordenação da atividade, por exigência do percurso. Seria metodologicamente mais consistente, se os prosseguimentos de análise pelo grupo, diante dos dados organizados pela observação, pudessem ser por eles mesmos criticados e qualificados de forma mais intensa.

Um paradoxo aparente - dado que não foi aprofundado - é que a análise de grupo sobre a compreensão conceitual que detinham e as contribuições externas dos convidados, encontraram as mesmas categorias, isto é a percepção ideológica, política ou técnica. Entretanto, assumindo aspectos mais amplos quando relacionados as proposições que formaram maioria no grupo, ao se tratar da participação em relação a construção de Cenários obteve-se uma ênfase na abordagem técnica. Quando no tema do Zoneamento Socioecológico de Mato Grosso, obteve-se a ênfase na abordagem política. 
Não é possível atribuir esse paradoxo exclusivamente a noção de informação imperfeita, mas é provocativa a ideia de que essas distinções merecem aprofundamento em razão dos compromissos teóricos e técnicos propostos pelo projeto do curso. Ficou evidente um gap de tempo para tratar desse assunto.

\section{CONCLUSÕES}

Exercícios como este demonstraram ser bastante produtivos, desafiadores e úteis se queremos aprofundar quais perspectivas pedagógicas que envolvam aprendizagens significativas e que se consolidem em razão de um propósito coletivo. Entretanto, no caso estudado, a análise da experiência demonstrou ser um processo incompleto do com ciclo de aprendizagem em grupo. De fato, pode haver aprendizagem, mas certamente não se referiu ao grupo. Talvez as subdivisões que se formam ou ao plano individual. O que leva a ponderar entre as decisões entre quem é o grupo e quem são os indivíduos que lideram ou interessam a ele.

Embora não tenha este propósito, estamos seguras que as propostas para registro reflexivo contidas nos diários ou scrap-book e no monitoramento coincidem com a visão de que a experiência e a observação precisam de um suporte "prático" para criar uma ponte e gerar consciência, de modo a que a conceitualização abstrata não se estabeleça ante uma ameaça de vazio e divagação permanente. Portanto, adaptando da proposta de Lizeo, consideramos que as atividades de aprendizagem experiencial e que a superação do gap é dada a partir do uso dessas ferramentas. Entretanto, esta tarefa se esvaziou durante o curso e, já no quarto módulo, não foi mais adotada de forma sistemática.

O sucesso dessas ferramentas atuarem por meio dos mapas cognitivos é discutível no plano geral do curso. Como dissemos foram abordagens en pasant, e as estratégias de avaliação eram privadas e direcionadas à gestão do curso. Apesar disto, este entendimento (presença de ferramentas) é útil para identificar qual ou como o processo reflexivo foi estimulado neste grupo, a partir da atividade que analisamos.

Em alguns momentos no transcurso da atividade, as perguntas relacionadas aos objetivos da proposta de observação participante no Plano de Aplicação, foram conduzidas no sentido de esperar o desenlace das circunstâncias do que serem levadas para o debate do grupão. Isto ocorre dada a dimensão conflituosa na própria natureza do Curso de Especialização, tanto em relação a visões sobre o conteúdo que se apresentavam como demandas, quanto para serem inseridas, avaliadas ou apropriadas. Os produtos gerados pelo curso contabilizam e 
demonstraram como, quanto e com quem os indivíduos preferiam ou optaram por interagir e, talvez, aprender.

Para poder analisar a emergência dos conceitos nos grupos, eles deveriam ser tratados como "percepções". E as categorias utilizadas, em conformidade com a dimensão teórica que pudessem ser defendidas durante a explicação e a escolha do grupo, na atividade. A compreensão determinou que participação, colaboração e gestão seriam expressões que envolveriam mais a percepção e experiência dos indivíduos, do que confrontos teóricos. Demonstrou o ambiente para rejeição do debate em torno do campo sob o qual os conceitos estão sendo propostos. A aprendizagem empírica desligava-se do aprofundamento teórico previsto para o curso em torno da teoria dos sistemas socioecológicos complexos.

A disseminação dos resultados e dos passos seguintes previstos na atividade consistiu em disponibilizar o relatório ao grupo de cursistas. A ideia era permitir o aprimoramento e/ou validação. Também houve a previsão de proporcionar um estudo acerca da colaboração - participação no estudo teórico, mas esta segunda sugestão não foi viabilizada. Transferida para o Módulo 4 também não pode ser executada. A sugestão foi definir as categorias que surgiram em relação ao conceito a partir do referencial de quem realizou o estudo. O Grupo se organizou e se mobilizou em direção aos proprios campos e subtemas.

Os conteúdos e as conclusões desta experiência e do grupo não puderam ser efetivamente tratados nas discussões do curso, por diversas razões legítimas e outras nem tanto. Nestas razões incluimos estarmos todos tateando sobre o tema bem como o reconhecimento dos limites do próprio curso quanto a sua condução ou conteúdo. Também convem lembrar as observações de Moon (2004) de que nem sempre a escrita sobre a aprendizagem experiencial consegue alcançar a profundidade de como e quando os sujeitos aprendem, mas talvez fiquem presos ou a como fazer o ciclo funcionar ou a verificar se o ciclo funciona. Faltaram-nos mais ferramentas.

A base da eficácia do ciclo é o diálogo. Um dado a este respeito é que na proposta do Curso, o diálogo foi integrado especialmente com base nas contribuições de Paulo Freire (1987; 1996), entretanto, com seu conteúdo "politizador" minimizado uma vez que a ação de aprendizagem estava justificada na palavra e no diálogo entre as pessoas, sem inferir sobre a condição ideológica que as posições e a palavra dos sujeitos guardavam. O que torna esta contribuição limitada e, em certos aspectos, discutível como veremos adiante.

A literatura sobre Paulo Freire enfatiza que o maior impacto de sua teoria é o reconhecimento de uma relação clara entre a existência de um opressor e um oprimido e que, por isto, são "não iguais" e não dialogam (BARRETO, 2004), 
dado que há impossibilidade de diálogo com quem usa de uma vantagem clara sobre alguém destituído de um bem cultural que, no caso de Paulo Freire (1987; 1996), refere-se à escolarização ou, no caso de atores e gestão, informação. Em outras circunstâncias pode-se admitir a existência um "diálogo" entre "não iguais" com foco na negociação, que foi por onde o curso pretendeu encaminhar o conceito de Freire, ao tratar de distintos atores e interesses.

De fato, os Ciclos de Aprendizagem funcionaram como mobilização cognitiva e vinculação eventual entre os indivíduos, o que se mostrou suficiente para demonstrar que a formação não enfrentou os dilemas da incursão na realidade em razão das práticas sociais. Isto torna essa experiência dependente de uma teoria de liderança que considere a participação/colaboração tanto como um conceito, quanto uma atitude. Em situações similares, nota-se que é necessário priorizar quais os compromissos formadores para obter articulações que gerem comunicação e pensamento articulado efetivo, reduzindo ou avaliando os eventos que geram os loops circunstanciais e produzam gaps de interesse e manipulação na própria aprendizagem. Entretanto, não há dúvida de que Kolb possui uma contribuição fundamental em propostas formadoras dessa natureza, caso sejam explicitas e incorporadas no grupo e/ou em um projeto.

\section{REFERÊNCIAS}

BARRETO, V. Paulo Freire para educadores. São Paulo: Arte \& Ciência, 2004. BRASIL, W. O projeto de aplicação. Curso de Especialização em Gestão Colaborativa. Porto Velho, RO, 2012. Disponível em <https://docs.google. $\mathrm{com} /$ viewer? $\mathrm{a}=\mathrm{v} \& \mathrm{pid}=$ sites\&srcid $=Z$ ZGVmYXVsdGRvbWFpbnxjdXJzb 3NlbWVudGV8Z3g6NzMyMTUwYmQ5ZmIxMGY1ZA> Acesso em 09 jan. 2013.

Conceitos e percepções de colaboração: bricolagens à reflexão sobre o tema gestão colaborativa. 2012. Monografia de Conclusão de Curso. Porto Velho, RO, 2012. Disponível em: <http://wwwacademia.edu/3569347/ Conceitos_e_Percepcoes_de_Colaboracao._Bricolagens _a_Reflexao_sobre_o_ Tema_da_Gestao_Colaborativa_2012_> Acesso em: Acesso em 09 jan. 2013.

FREIRE, P. Pedagogia da autonomia: saberes necessários à prática educativa. São Paulo: Paz e Terra, 1996.

Pedagogia do oprimido. 17. ed. Rio de Janeiro: Paz e Terra, 1987. 
KOLB, D. A. Experiential Learning. Experience as the Source of Learning and Development. Englewood Cliffs, NJ: Prentice Hall, 1984. Disponível em: <http:/ / academic.regis.edu/ed205/kolb.pdf> Acesso em: 13 jul. 2011.

LIZEO, E. Um modelo dinâmico de aprendizagem em grupo. 2003. $163 f$. Tese (Doutorado em Administração de Empresas) - Escola de Administração de Empresas de São Paulo, Fundação Getúlio Vargas, São Paulo, 2003.

MARKOVÁ, I. Dialogicidade e representações sociais: as dinâmicas da mente. Petrópolis-RJ: Vozes, 2006.

MOON, J. A handbook of reflective and experiencial learning. theory and practice. London: RoutledgeFarm. (PDF). 2004. Disponível em: < http:// perpustakaandeajulia.weebly.com/uploads/1/8/2/6/18261275/a_handbook_ of_reflectiv e_and_experiential_learning_-_theory_and_practice.pdf $>$ Acesso em: 13 jul. 2011.

MORIN, E. Introdução ao pensamento complexo. Tradução: Eliane Lisboa. 3. ed. Porto Alegre: Sulina, 2007.

OSTROM, E. A general Framework for Analyzing Sustainnatility of SocialEcological Systems. Science, 324, p. 419-422, 2009.

PIMENTEL, A. A teoria da aprendizagem experiencial como alicerce de estudos sobre desenvolvimento profissional. Estud. Psicol., Natal, v. 12, n. 2, p.159168, 2007. http://dx.doi.org/10.1590/S1413-294X2007000200008. Disponível em: <http://www.scielo.br/pdf/epsic/v12n2/a08v12n2.pdf>. Acesso em: 9 jul. 2013.

RUAS, R.; ANTONELLO, C. S.; BOFF, L. H. (Org.). Os novos horizontes da gestão: aprendizagem organizacional e competências. Porto Alegre: Bookman, 2005.

SOUZA E SILVA, M. C. P. de; KOCK, I. G. V. Línguística Aplicada ao Português: Sintaxe. São Paulo: Cortez, 1989.

SIQUEIRA, M. et al. Medidas do comportamento organizacional. ferramentas de diagnóstico e de gestão. Porto Alegre: Bookman, Artmed, 2008. 